\title{
PRL-3 promotes the motility, invasion, and metastasis of LoVo colon cancer cells through PRL-3-integrin $\beta$ I-ERKI/2 and-MMP2 signaling Lirong Peng ${ }^{\dagger}$, Xiaofang Xing ${ }^{\dagger}$, Weijun $\mathrm{Li}^{\dagger}$, Like Qu, Lin Meng, Shenyi Lian, Beihai Jiang, Jian Wu and Chengchao Shou*
}

Address: Key Laboratory of Carcinogenesis and Translational Research (Ministry of Education), Department of Biochemistry and Molecular Biology, Peking University School of Oncology, Beijing Cancer Hospital \& Institute, Beijing 100142, PR China

Email: Lirong Peng - lrpeng@hotmail.com; Xiaofang Xing - bubblefangfang@gmail.com; Weijun Li - liweijun83@bjmu.edu.cn; Like Qu - qulike@bjcancer.org; Lin Meng - menglin3330@sina.com; Shenyi Lian - liansy@bjmu.edu.cn; Beihai Jiang - sallybeihai@sina.com JianWu -wujian997@sina.com; Chengchao Shou* - scc@bjcancer.org

* Corresponding author †Equal contributors

Published: 24 November 2009

Molecular Cancer 2009, 8:1 I0 doi:10.1 186/1476-4598-8-110
Received: I July 2009

Accepted: 24 November 2009

This article is available from: http://www.molecular-cancer.com/content/8/1/II0

(c) 2009 Peng et al; licensee BioMed Central Ltd.

This is an Open Access article distributed under the terms of the Creative Commons Attribution License (http://creativecommons.org/licenses/by/2.0), which permits unrestricted use, distribution, and reproduction in any medium, provided the original work is properly cited.

\begin{abstract}
Background: Phosphatase of regenerating liver-3 (PRL-3) plays a causative role in tumor metastasis, but the underlying mechanisms are not well understood. In our previous study, we observed that PRL-3 could decrease tyrosine phosphorylation of integrin $\beta I$ and enhance activation of ERKI/2 in HEK293 cells. Herein we aim to explore the association of PRL-3 with integrin $\beta$ I signaling and its functional implications in motility, invasion, and metastasis of colon cancer cell LoVo.

Methods: Transwell chamber assay and nude mouse model were used to study motility and invasion, and metastsis of LoVo colon cancer cells, respectively. Knockdown of integrin $\beta \mathrm{I}$ by siRNA or lentivirus were detected with Western blot and RT-PCR. The effect of PRL-3 on integrin $\beta I, E R K I / 2$, and MMPs that mediate motility, invasion, and metastasis were measured by Western blot, immunofluorencence, co-immunoprecipitation and zymographic assays.

Results: We demonstrated that PRL-3 associated with integrin $\beta I$ and its expression was positively correlated with ERKI/2 phosphorylation in colon cancer tissues. Depletion of integrin $\beta$ I with siRNA, not only abrogated the activation of ERKI/2 stimulated by PRL-3, but also abolished PRL-3-induced motility and invasion of LoVo cells in vitro. Similarly, inhibition of ERKI/2 phosphorylation with U0I 26 or MMP activity with GM600I also impaired PRL-3-induced invasion. In addition, PRL-3 promoted gelatinolytic activity of MMP2, and this stimulation correlated with decreased TIMP2 expression. Moreover, PRL-3-stimulated lung metastasis of LoVo cells in a nude mouse model was inhibited when integrin $\beta I$ expression was interfered with shRNA.
\end{abstract}

Conclusion: Our results suggest that PRL-3's roles in motility, invasion, and metastasis in colon cancer are critically controlled by the integrin $\beta$ I-ERKI/2-MMP2 signaling. 


\section{Background}

Colorectal cancer ranks third in the incidence of cancer in the world, and metastasis is the main death cause. Although causes and genetic bases of tumorigenesis vary greatly, key events required for metastasis are similar, including alteration of adhesion ability, enhancement of motility, and secretion of proteolytic enzymes to degrade extracellular matrix (ECM) and vascular basement membrane; all these steps are orchestrated by a plethora of signaling events. Phosphatase of regenerating liver-3 (PRL3), also known as PTP4A3, encodes a 22-kilodalton protein tyrosine phosphatase and is characteristic of a CAAX motif for prenylation at the carboxyl terminus [1]. At mRNA level, it is detected primarily in skeletal and cardiac muscles, somewhat in pancreas, but rarely in brain, lungs, liver, kidneys, and placenta [2]. However, it is highly expressed in multiple cancer cell lines and vascular endothelial cells [3-5]. Initially, PRL-3 was found to be up-regulated in liver metastases of colorectal cancer, but was low or absent in normal colorectal epithelium, adenoma, and primary lesions [6]. Later, we and other several groups provided strong evidence to show that PRL-3 is overexpressed in diverse malignancies, including colorectal, breast, gastric, and ovarian cancers, and its expression is correlated with disease progression and survival [7-14]. A recent study by Molleví et al. demonstrated that tumor microenvironment play a critical role in regulating PRL-3 expression[15]. To date, PRL-3 is not only thought as a potential prognostic factor for diagnosis and survival of multiple type cancers, but also has a therapeutic implication, because its expression at the invasive margin of tumor predicted resistance to radiotherapy and unfavorable survival for patients [16,17].

Previous studies also revealed that PRL-3 plays a causative role in promoting cell motility, invasion, and metastasis $[18,19]$. However, little is known about the molecular mechanisms by which PRL-3 promotes motility, invasion and metastasis. It was reported that PRL-3 exerted its functions by regulating Rho family GTPase [20], activating Src [21], and modulating PI3K-Akt pathway [22] in a contextdependent manner. In addition, a transcriptional regulation of PRL-3 by p53 has been reported [23]. In our previous study, we found a physical association between PRL3 and integrin $\alpha 1$ by yeast two-hybrid and GST-pull down assays [24]. We also observed decreased tyrosine phosphorylation of integrin $\beta 1$ and enhanced phosphorylation of extracellular signal-regulated kinase 1/2 (ERK1/2) in exogenous PRL-3-stably expressing HEK293 cells. Integrins is a large family of heterodimeric cell-surface receptors and integrin-mediated extracellular signals stimulate a variety of intracellular signaling events, including tyrosine phosphorylation and mitogen-activated protein kinase (MAPK) cascades, leading to the ERK activation, which is involved in cell survival and proliferation, and promotes metaplasia and tumor development [25-28]. Therefore, in the present study, we investigated the functional roles of integrin signaling and ERK1/2 activation in PRL-3-promoted motility, invasion, and metastasis in colon cancer cell LoVo. We verified the enhancement of ERK1/2 phosphorylation in PRL-3-stably expressing LoVo (LoVo-P) cells. Knockdown of integrin $\beta 1$ not only inhibited PRL-3-induced ERK1/2 phosphorylation, but also abrogated PRL-3-mediated motility, invasion, and lung metastasis in nude mice. In the downstream of integrin $\beta 1$ pathway, ERK1/2 phosphorylation and MMP2 activity were found to be responsible for PRL-3-mediated cell invasion. Collectively, our study demonstrated that the integrin $\beta 1$-ERK1/2 and -MMP2 signaling plays critical roles in PRL-3-promoted motility, invasion, and metastasis of colon cancer cells.

\section{Methods \\ Reagents and cell culture}

We purchased anti-integrin $\beta 1$ anitbody (MAB 1965) from Chemicon (Temecula, CA). Anti-phosphorylated tyrosine antibody 4G10 was from Millipore (Billerica, MA). Monoclonal antibody 3B6 against PRL-3 was generated as previously described [29]. Polyclonal antibody to PRL-3 was from Sigma. Antibodies against ERK1/2 and phosphorylated ERK1/2 (p-ERK1/2) were from Upstate (Beverly, MA). Anti-p53 antibody (DO-1) was from Santa Cruz. U0126 was from Cell Signaling (Beverly, MA). Colon cancer cell line LoVo (ATCC, Manassas, VA) were maintained in Ham's F12K medium (Invitrogen) supplemented with $10 \%$ fetal calf serum.

\section{Plasmids and transfection}

Myc-tagged human PRL-3 cDNA was inserted into pcDNA3. 1 at BamH I/Xba I sites to generate a mammalian expression plasmid pcDNA3.1-PRL-3. Then, pcDNA3.1PRL-3 and pcDNA3.1 were transfected into LoVo cells with Lipofectamine 2000 (Invitrogen) to generate PRL-3stably expressing and control cells, respectively. After 4 weeks of selection with $600 \mu \mathrm{g} / \mathrm{mL}$ of Geneticin (Invitrogen), expression of PRL-3 was verified by RT-PCR and Western blot. Plasmid pEGFP-C1-PRL-3 was generated by ligating BamH I/EcoR I digested full-length PRL-3 to Bgl II/EcoR I digested pEGFP-C1 vector (Clontech, Palo Alto, CA).

\section{RNA interference}

Integrin $\beta 1$-specific siRNA, synthesized by Sigma-Aldrich Corporation (St. Louis, MO), was designed to silence all splices of human integrin $\beta 1$ mRNA. The sequence was: sense, 5'-GGAAAUGGUGUUUGCAAGUdTdT-3'; antisense, 5'-ACUUGCAAACACCAUUUCCdTdT-3'. It was scrambled to generate a negative control. Lentivirus vectors expressing short hair-pin (sh)RNA targeting PRL-3 or integrin $\beta 1$ were constructed, packed, and purified by 
GeneChem Corporation (Shanghai, China), and was manipulated according to the Biological Institutional Committee of Beijing.

\section{Western blot and immunoprecipitation}

Cells were homogenized in lysis buffer ( $50 \mathrm{mM}$ Tris- $\mathrm{HCl}$, pH 7.5, $150 \mathrm{mM} \mathrm{NaCl}, 1 \% \mathrm{NP}-40,1 \mathrm{mM}$ DTT, $1 \mathrm{mM}$ phenylmethylsulfonyl fluoride, $10 \mathrm{mM} \mathrm{NaF}, 1 \mathrm{mM} \mathrm{Na}_{3} \mathrm{VO}_{4}$, $1 \times$ protease cocktail) for $20 \mathrm{~min}$ at $4{ }^{\circ} \mathrm{C}$. The supernatant was collected after centrifugation at $12,000 \times \mathrm{g}$ for $20 \mathrm{~min}$ at $4{ }^{\circ} \mathrm{C}$ and subjected to Western blot or immunoprecipitation as previously described [24]. Documentation of blots was performed by scanning with an EPSON PERFECTION 2580 scanner and acquired images were adjusted by the Auto-Contrast command of Photoshop CS (Adobe, San Jose, CA).

\section{Immunohistochemical analysis}

Consecutive 4- $\mu \mathrm{m}$ paraffin-embedded sections of colon cancer tissues were obtained from the Department of Pathology of the Beijing Cancer Hospital and Institute. Staining of PRL-3 or p-ERK1/2 protein by an immunohistochemical assay was performed as previously described [7]. Specimens with more than $10 \%$ positive-staining cancer cells were classified as positive.

\section{Motility and invasion assays}

For transwell chamber-based motility and invasion assays, equal amounts of cells were loaded into an insert provided with serum-free medium and allowed to pass through an 8 - $\mu \mathrm{m}$-pore polycarbonate filter, which had been either pre-coated with $100 \mu \mathrm{g}$ of Matrigel (Becton Dickinson, San Jose, CA) for invasion assay or left uncoated for motility assay. Medium supplemented with $10 \%$ fetal calf serum was added to the bottom chamber. Cells on the upper surface of filters were wiped out after $24 \mathrm{~h}$ (motility assay) or $48 \mathrm{~h}$ (invasion assay), and those on the undersurface were stained with $1 \%$ amino toluene blue and counted under a microscope.

\section{In vitro wound healing assay}

Cells were seeded onto 6-well plates at a sub-confluent density. After $12 \mathrm{~h}$, a line was scrapped out on the cell monolayer by a $200-\mu$ l pipet tip and the width of this wound line was photographed using an inverted microscope (ECLIPSE TS100, Nikon, Japan) at a $24 \mathrm{~h}$ interval. The motility speed of cells was assessed by the healing degree of the wound line. The experiment was repeated three times independently.

\section{Indirect immunofluorescence}

To visualize green fluorescent protein (GFP) tagged PRL3, LoVo cells were transfected with pEGFP-C1-PRL-3 and seeded onto coverslips. For indirect immunofluorescence assays, pEGFP-C1-PRL-3 transiently transfected LoVo cells were fixed with $4 \%$ paraformaldehyde for $10 \mathrm{~min}$ at room temperature, permeabilized with $0.5 \%$ Triton X-100/ phosphate-buffered saline for $5 \mathrm{~min}$, and blocked with $3 \%$ bovine serum albumin for $30 \mathrm{~min}$. Anti-integrin $\beta 1$ antibody was then added to the cells, followed with a tetramethyl rhodamine isothiocyanate-conjugated secondary antibody. After washing with phosphate-buffered saline/Tween-20, coverslips were mounted on glass slides with $50 \%$ glycerol/phosphate-buffered saline and imaged using a Leica SP2 confocal system (Leica Microsystems, Dresden, Germany).

\section{Metastasis study}

We performed animal experiments in accordance with the Experimental Animal Management Ordinance approved by the Scientific and Technological Committee of China. Every of the five experimental groups had eight 4 to 6week-old female nude BALB/c mice (Lian-Tong-Li-Hua Corporation, Beijing, China). Each mouse was injected via tail vein with $2.5 \times 10^{6} \mathrm{LoVo}$ control (LoVo-C) or LoVo-PRL-3 (LoVo-P) cells; the latter were pre-infected with lentivirus interfering with PRL-3, integrin $\beta 1$, or mock control, respectively. Two months later, all animals were sacrificed, and 4- $\mu \mathrm{M}$ paraffin-embedded sections of lung and liver tissues were prepared. The sections were stained with hematoxylin and eosin and examined for the presence of metastatic tumor foci under a microscope.

\section{Zymographic analysis}

The zymographic analysis was adapted from Surgucheva IG et al. [30]. Cells were grown to $70-80 \%$ confluence on $10-\mathrm{cm}$ plates, washed twice with PBS, and cultured in serum-free medium for another $36 \mathrm{~h}$. Next, medium was concentrated to one-tenth volume and measured for protein concentration. Appropriate volume of medium with equivalent amount of protein was subjected to electrophoresis in $10 \%$ gel containing $0.1 \%$ gelatin. After electrophoresis, the gelatin gel was washed twice with $2.5 \%$ Triton X-100 and allowed to perform an enzyme reaction in Tris buffer ( $50 \mathrm{mM}$ Tris- $\mathrm{HCl}$ at pH 7.4, $200 \mathrm{mM} \mathrm{NaCl}$, and $10 \mathrm{mM} \mathrm{CaCl}_{2}$ ) overnight at $37^{\circ} \mathrm{C}$. Next, it was stained with 0.5\% Coomassie Brilliant Blue R-250 and de-stained with $5 \%$ acetic acid containing $10 \%$ methanol.

\section{Statistical analysis}

Statistical analysis software package SPSS 12.0 (SPSS Inc., Chicago, IL) was used to perform Poisson distribution events test and Chi-square test. P value less than 0.05 was considered statistically significant.

\section{Results}

\section{PRL-3 is associated with integrin I}

In a previous study, we found a physical interaction between PRL-3 and integrin $\alpha 1$ [24]. As a membrane receptor, integrin $\alpha 1$ can heterodimerize with different 
members of integrin $\beta$ family, including integrin $\beta 1$, to initiate signaling transduction. It is usually thought that integrin $\alpha$ subunit is associated with ECM adhesion, while $\beta$ subunit is mainly responsible for signal transduction [31]. To understand the functional relevance of the association between PRL-3 and integrin signaling, we firstly transfected PRL-3 cDNA or vector control into human colon cancer cell line LoVo, which has no detectable PRL3 protein expression even in the presence of genotoxic stress by Adriamycin [see Additional file 1], which stabi- lized p53, a known PRL-3 inducer at transcriptional level [23]. After selection with Geneticin, stable expression of Myc-tagged PRL-3 in LoVo-P cells was verified by Western blot (Figure 1A) and RT-PCR (data not shown). Next, we examined the interaction between PRL-3 and integrin $\beta 1$ by immunoprecipitating PRL-3 with anti-Myc antibody, followed by immunoblotting with anti-integrin $\beta 1$. Integrin $\beta 1$ was observed in precipitates of LoVo-P cells but not in that of LoVo-C cells (Figure 1A), indicating that PRL-3 assocaited with integrin $\beta 1$ in LoVo cells.

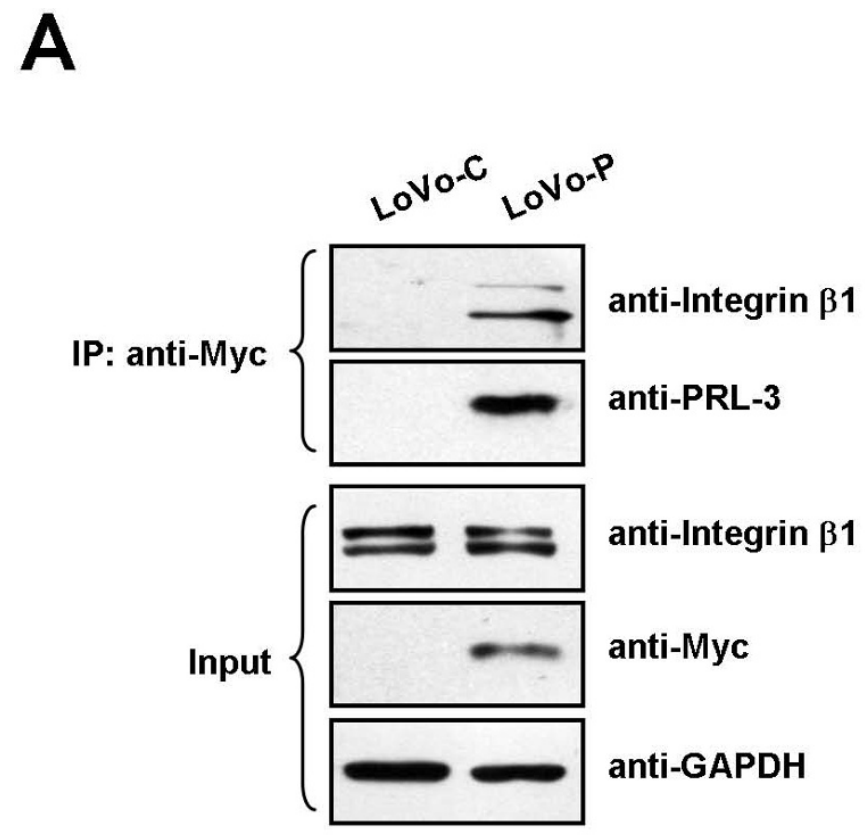

B
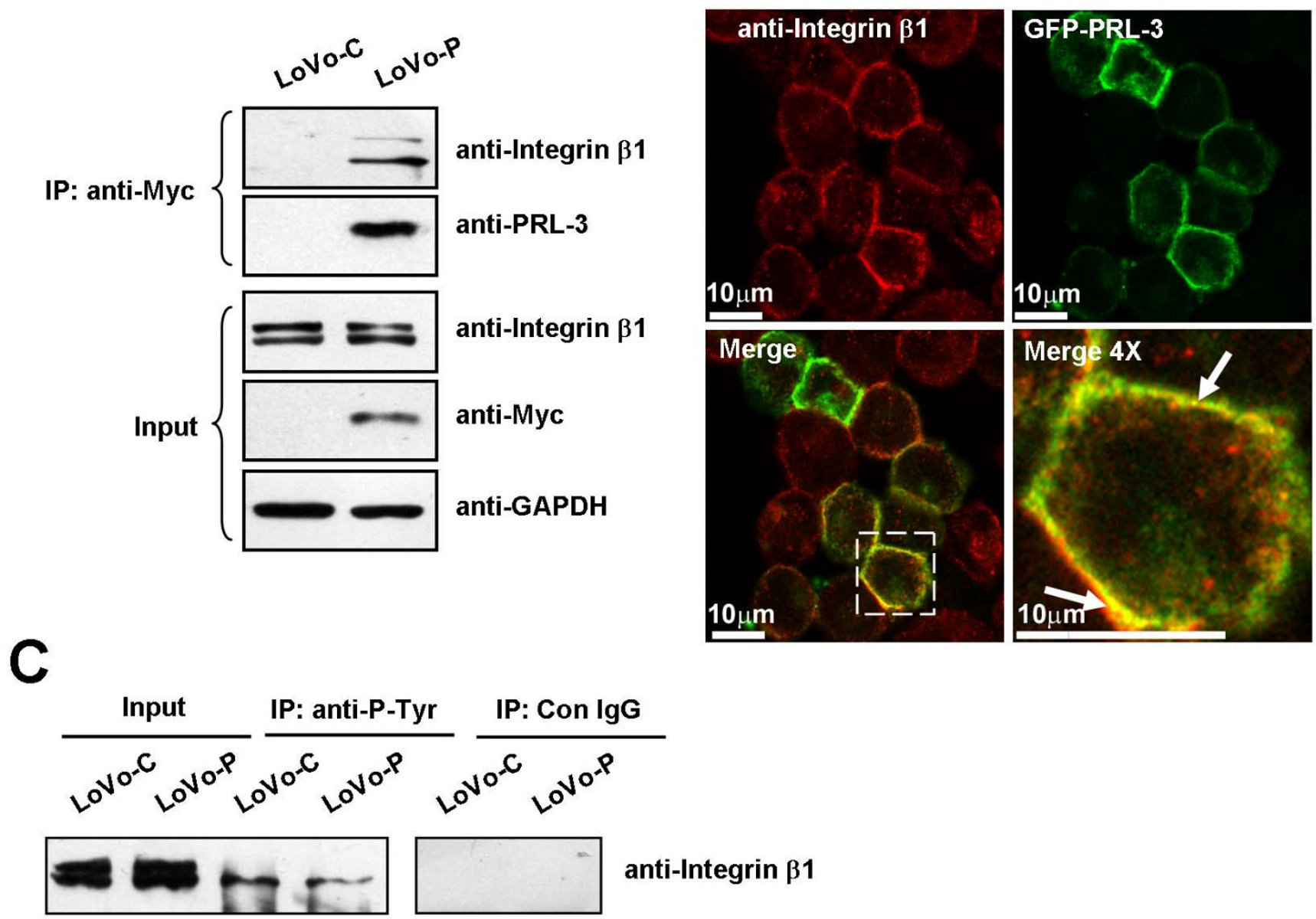

Figure I

PRL-3 interacts with integrin $\beta I$ and decreases its tyrosine phosphorylation in LoVo cells. (A) PRL-3 interacted with integrin $\beta$ I. Equal amount of lysates $(500 \mu \mathrm{g}$ of protein) from LoVo-P cells, which stably expressed myc-tagged human PRL-3, and control LoVo-C cells were immunoprecipitated with anti-myc antibody, followed by Western blot with anti-integrin $\beta I$ antibody and anti-PRL-3 antibody. Expression of integrin $\beta I$ and PRL-3 in the lysates (50 $\mu g$ of protein) was shown as Input. GAPDH protein expression was shown as a loading control. Molecular weight was shown. (B) PRL-3 was colocalized with integrin $\beta$ I. LoVo cells were transiently transfected with GFP-PRL-3 (green). Twenty-four hours after transfection, cells were fixed, stained with an anti-integrin $\beta I$ antibody (red), and observed under a laser confocal microscope. The white arrow in Merge (4x) indicates the colocalization of PRL-3 with integrin $\beta$ I (yellow). (C) PRL-3 decreased tyrosine phosphorylated integrin $\beta$ I. Equal amount of lysates $(500 \mu \mathrm{g}$ of preotein) from LoVo-C and LoVo-P cells were immunoprecipitated with antiphosphotyrosine antibody or IgG control. The precipitates were subjected to Western blot with anti-integrin $\beta$ I. 
To better support this result, we examined subcellular localization of transiently overexpressed GFP-tagged PRL3 and endogenous integrin $\beta 1$ in LoVo cells by an indirect immunofluorescence assay. Figure 1B showed that both GFP-tagged PRL-3 and fluorescent antibody-labeled integrin $\beta 1$ were expressed in cytoplasmic membrane. Dual-color merged confocal imaging demonstrated that PRL-3 was colocalized with integrin $\beta 1$ (Figure 1B).

Previously, we noticed a decrease of integrin $\beta 1$ tyrosine phosphorylation in PRL-3-stably expressing HEK293 cells [24]. Therefore, we checked the effect of PRL-3 on tyrosine phosphorylation of integrin $\beta 1$ in LoVo cells. Using equal amount of lysates from LoVo-C and LoVo-P cells, we immunoprecipiated tyrosine-phosphorlyated integrin $\beta 1$ with a phospho-tyrosine specific antibody, respectively, and immunoblotted it with anti-integrin $\beta 1$ antibody. Tyrosine-phosphorylated integrin $\beta 1$ was found in both cells, however, it was decreased in LoVo-P cells (Figure $1 C)$, though integrin $\beta 1$ protein expressed at similar level. This result substantiated PRL-3's role in regulating tyrosine phosphorylation of integrin $\beta 1$.

\section{Integrin I is necessary for PRL-3-induced cell motility and invasion in vitro}

Integrins are involved in diverse malignant phenotypes of tumor, including invasion and metastasis [32]. PRL-3 is also crucial for cancer cell motility, invasion, and metastasis [18]. Considering the association between PRL-3 and integrin $\beta 1$ found above, we investigated the requirement of integrin $\beta 1$ for PRL-3-promoted cell motility and invasion. To this end, cells were treated with a small interfering RNA (siRNA) against integrin $\beta 1$ or a control siRNA. After confirmation of silencing efficiency by RT-PCR and Western blot (Figure 2A), migrating and invasive capacities of LoVo-C and LoVo-P cells were analyzed with transwell chambers as described in Experimental Procedures. Consistent with previous studies with other cancer cell lines $[18,19]$, PRL-3 enhanced LoVo cell motility and invasion (Figure 2B). However, knockdown of integin $\beta 1$ significantly impaired the migrating and invasive abilities of LoVo-P cells $\left({ }^{*}, \mathrm{P}<0.05\right.$, Figure $2 \mathrm{~B}$ and $\left.2 \mathrm{C}\right)$, but not those of LoVo-C cells. To further validate these results, we performed wound healing assay. As shown in Additional file 2, the speed of wound healing of LoVo-P cells was faster than that of LoVo-C cells. By $72 \mathrm{~h}$ after wounding, the wound of LoVo-P were almost closed up, while those of LoVo-C cells were still wide apart. However integrin $\beta 1$ inhibition substantially abolished the effect of PRL-3.

Integrin $I$ is required for PRL-3-induced metastasis in vivo Given the role of integrin $\beta 1$ in mediating PRL-3's in vitro effect on cell motility and invasion, we further examined the requirement of integrin $\beta 1$ for PRL-3-mediated metastasis in nude mouse BALB/c, which are immunodeficient and susceptible to tumor formation and metastasis. First, lentivirus interfering with expression of PRL-3 or integrin $\beta 1$ was generated, respectively, and their silencing efficiencies were verified by RT-PCR and Western Blot (Figure 3A). Next, LoVo-P cells were infected with control-, PRL$3-$, or integrin $\beta 1$-interference lentivirus for $48 \mathrm{~h}$. Then each nude mouse was injected via tail vein with $2.5 \times 10^{6}$ LoVo-C or LoVo-P cells, which had been infected with lentivirus or not as listed in Table 1. Two months later, nude mice were sacrificed and dissected. No macroscopic tumors were found in all organs of the dissected mice (data not shown). Livers and lungs were isolated, fixed with formalin, and prepared for 4 - $\mu \mathrm{m}$ paraffin-embedded slices. The slices were stained with hematoxylin and eosin, and subjected to microscopic observation for metastatic foci. No metastatic tumor was found in livers of all groups (data not shown), possibly due to minimally hepatophilic property of LoVo cells. As shown in Table 1, 13 and 8 lung metastatic foci were respectively found in uninfected LoVo-P group and control-lentivirus infected LoVo-P group, whereas none was found in LoVo-C group $\left({ }^{*}, \mathrm{P}<\right.$ $0.05)$. Though control-lentivirus infected LoVo-P group formed less metastatic foci than uninfected LoVo-P group, there was no statistical significance $(P>0.05)$. This difference might result from the side effects of lentivirus infection. However, there was only 1 metastatic tumor formed in PRL-3-interference LoVo-P and integrin $\beta 1$-interference LoVo-P groups $\left({ }^{*}, \mathrm{P}<0.05\right.$, compared to control-lentivirus LoVo-P group), respectively. The representative illustrations of hematoxylin and eosin staining were demonstrated in Figure 3B. These results support that integrin $\beta 1$ is crucial for PRL-3-promoted metastasis in vivo.

Integrin $I$ is required for PRL-3-induced ERKI/2 activation We previously found that overexpression of PRL-3 activated ERK1/2 in HEK293 cells [24]. We also obtained a similar result in LoVo cells (Figure 4A). ERK is an important signal transducer triggered by integrin and is closely implicated in ECM-dependent cell motility [33-35]. To examine the relevance of PRL-3 with ERK1/2 activity in colon cancer, expression of PRL-3 and p-ERK1/2 in 11 pairs of consecutive $4-\mu \mathrm{m}$ primary lesions from sporadic colon cancer patients was evaluated by an immunohistochemical assay with anti-PRL-3 and anti-p-ERK1/2 antibodies, respectively. The representative staining of PRL-3 and p-ERK1/2 in tumor tissue slices is shown in Figure 4B. We found 4 of 5 (90\%) PRL-3-expressing samples simultaneously expressed p-ERK1/2, whereas 5 of $6(83.3 \%)$ PRL-3-negative samples were p-ERK1/2-negative either. Statistic analysis (Chi-square test) showed that expression of p-ERK1/2 was positively correlated with that of PRL-3 in colon cancer (see Additional file $3 ;{ }^{*}, \mathrm{P}<0.05$ ). Interestingly, knockdown of integrin $\beta 1$ abolished PRL-3induced phosphorylation of ERK1/2 in LoVo-P cells (Fig- 

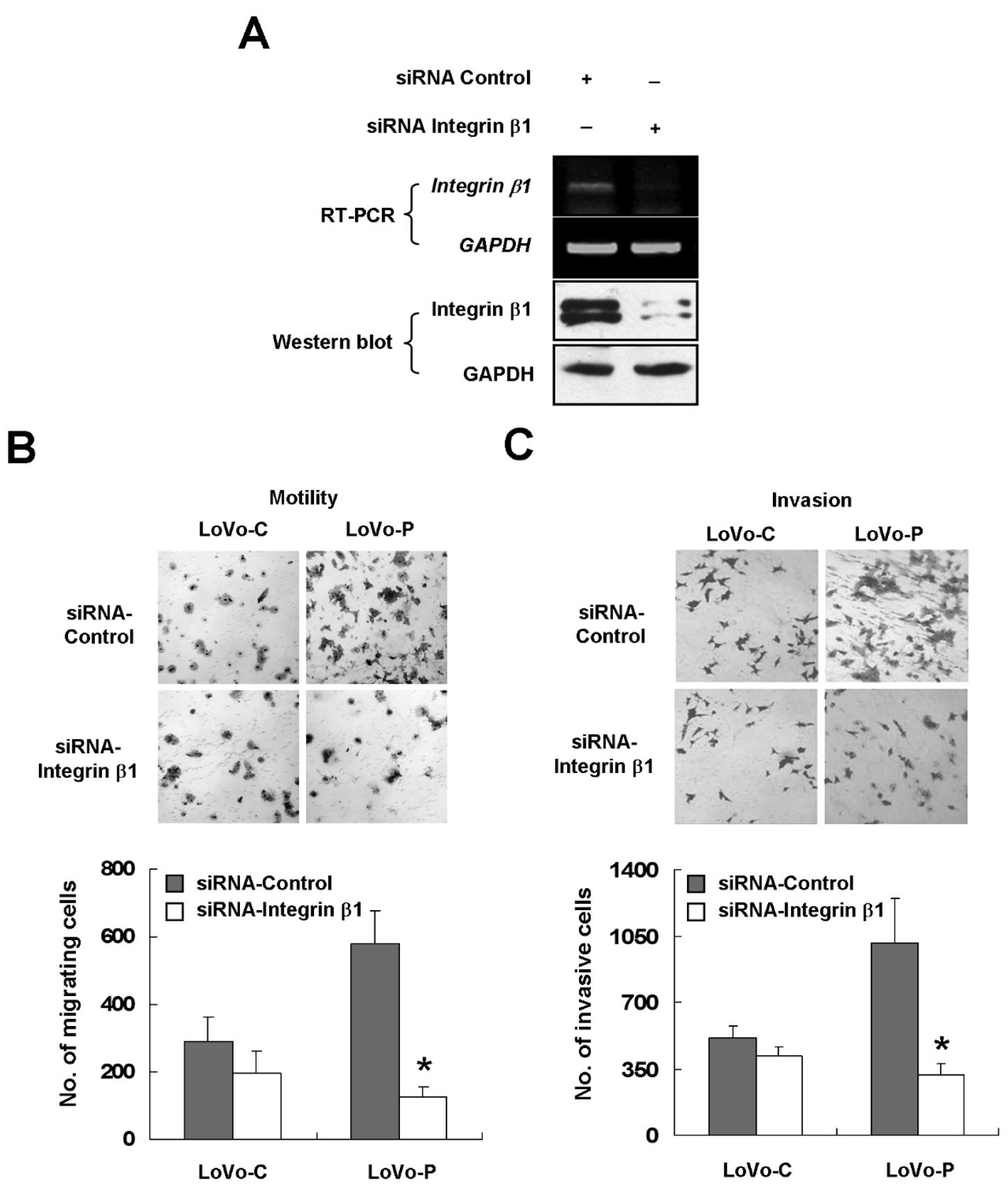

\section{Figure 2}

Integrin $\beta$ I mediates PRL-3-induced cell motility and invasion. (A) LoVo-P cells were treated with siRNA specific for integrin $\beta$ I or control. Seventy-two hours after transfection, cells were harvested. Equal amount of protein lysates (50 $\mu \mathrm{g}$ of protein) was analyzed for integrin $\beta I$ protein expression and RNA was extracted for RT-PCR. (B) and (C) Integrin $\beta I$ is required for PRL-3-induced cell motility and invasion. Cells were transfected with indicated siRNAs as in (A). Seventy-two hours after transfection, cells were analyzed for their motility and invasion with the use of transwell chambers. Cells were suspended in serum-free medium and loaded at a density of $2.5 \times 10^{4}$ to an insert of a transwell chamber, and those migrating or invading to the underside of filtera were stained and counted after $24 \mathrm{~h}$ (B, motility assay) or $48 \mathrm{~h}$ ( $\mathrm{C}$, invasion assay). Top panel: Representative illustrations for motility and invasion assays (original magnification, $\times 200$ ). Bottom panel: Quantification of migrating and invasive cells. Values were the total number of stained cells. The experiments were repeated at least three times independently. Error bars represent standard errors of the mean value $(*, P<0.05)$. 
ure $5 \mathrm{~A})$, raising the possibility that integrin $\beta 1$ is an intermediate transducer between PRL-3 and ERK1/2 signaling pathway. Now that depletion of integrin $\beta 1$ decreased PRL-3-promoted cell motility and invasion and ERK1/2 activation (Figure $2 \mathrm{~B}$ and $2 \mathrm{C}$ ) but had no effect on protein level of PRL-3 (Figure 5A), we sought to examine effects of selective inhibition of ERK1/2 in the same cellular context. LoVo cells were treated with $10 \mu \mathrm{M}$ of the ERK1/2 inhibitor U0126, the concentration of which was sufficient to abrogate ERK1/2 phosphorylation but neither the protein levels of PRL-3 (Figure 5B) nor integrin $\beta 1$ (data not shown) in LoVo-P cells. We found that ERK1/2 inhibition significantly reduced PRL-3-promoted motility and invasion of LoVo-P cells ( $*, \mathrm{P}<0.05$, Figure 5C, D), while those of LoVo-C cells were not affected. Thus, we conclude that ERK1/2 signaling is also crucial for functions of PRL-
3, and importantly, integrin $\beta 1$ mediates the signaling between PRL-3 and ERK1/2.

\section{PRL-3 promotes cell invasion by altering the balance between MMP2 and TIMP2}

We have shown that PRL-3 promoted invasion of LoVo cells through integrin $\beta 1$-mediated ERK1/2 signaling. Invasion is a key process of cancer cell metastasis. It is involved with secreting proteolytic enzymes, including Matrix metalloproteinase (MMPs), to degrade ECM and basement membranes. MMPs are capable of degrading all components of ECM and play important roles in tumor metastasis [36,37]. It was reported that MMPs could be activated by integrin and ERK signaling [38-41]. Therefore, we first examined the requirement of MMPs activity for PRL-3-mediated invasion. LoVo-C and LoVo-P cells

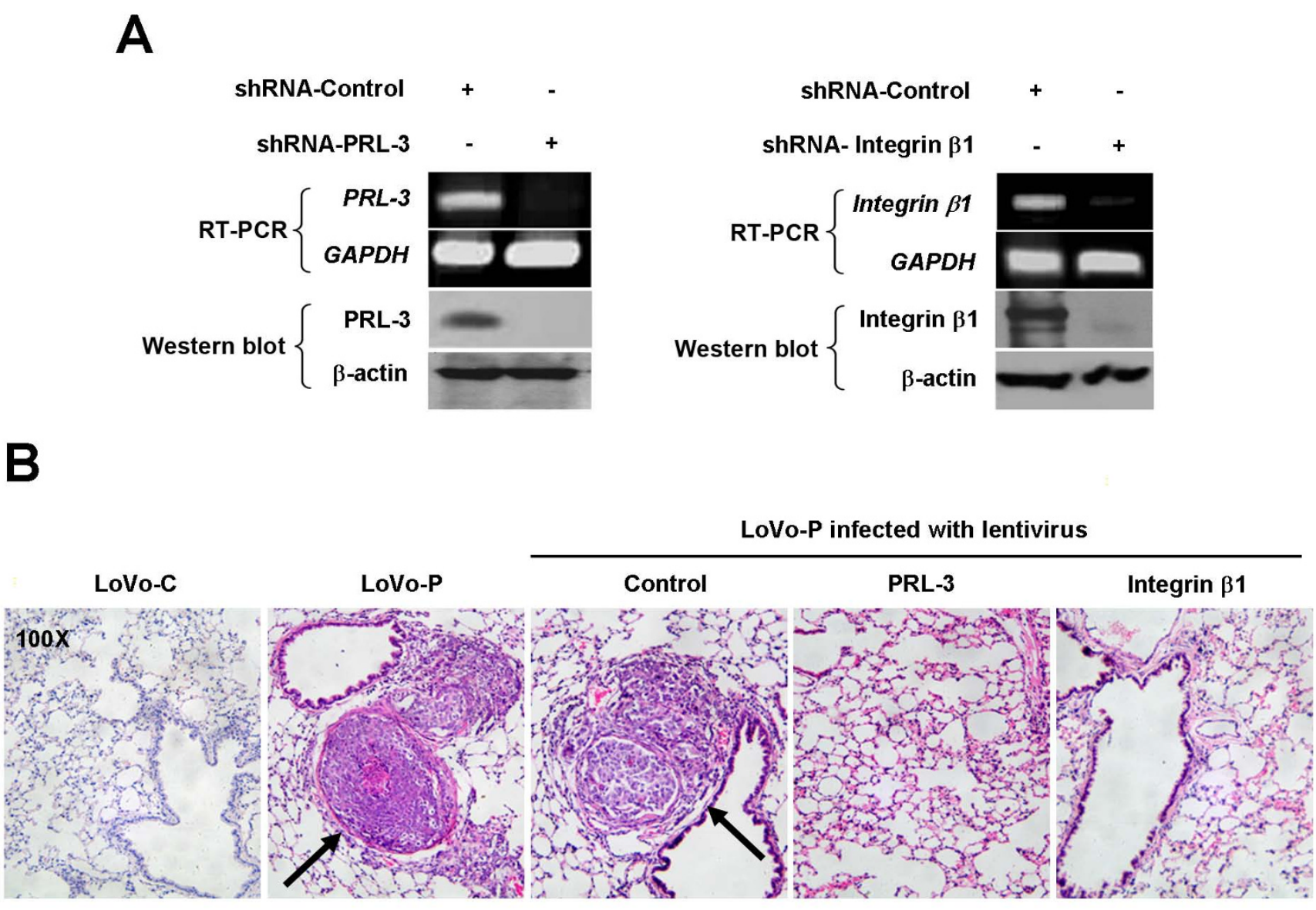

Figure 3

Depletion of integrin $\beta$ I or PRL-3 abrogates PRL-3-promoted metastasis in vivo. LoVo-P cells were infected with lentivirus interfering with PRL-3, integrin $\beta$ I, or control respectively at a multiplicity of infection value of $100 \mathrm{for} 48 \mathrm{~h}$, or left untreated. (A) Validation of silencing efficiency of Lentivirus by RT-PCR and Western blot. (B) Each nude BALB/c mouse was injected via the tail vein with $2.5 \times 10^{6}$ LoVo-C or LoVo-P cells. Two months later, mice were sacrificed, and 4- $\mu \mathrm{m}$ paraffin slices of liver and lung tissues were stained with hematoxylin and eosin dyes and examined under a light microscope. Arrows indicate the presence of a metastatic tumor in a lung slice. 
Table I: Metastasis of LoVo-C and LoVo-P Cells in Nude Mice BALB/c

\begin{tabular}{lccc}
\hline Group & Total number of mice & Number of mice with metastasis & Number of metastatic foci \\
\hline LoVo-C uninfected & 8 & 0 & $0 *$ \\
LoVo-P uninfected & 8 & 4 & 13 \\
LoVo-P lentivirus-control & 8 & 4 & 8 \\
LoVo-P lentivirus-integrin $\beta 1$ & 8 & 1 & $1 *$ \\
LoVo-P lentivirus-PRL-3 & 8 & 1 & $1 *$ \\
\hline
\end{tabular}

$* P<0.05$ when compared to LoVo-P lentivirus-control

Statistical analysis was performed with Poisson distribution events test

were treated with the MMPs inhibitor GM6001 and analyzed for invasion abilities with transwell chambers. Figure 6A showed that GM6001 significantly reduced PRL-3induced invasion in LoVo-P $(*, \mathrm{P}<0.05)$, but not in LoVo-C, supporting a functional link between PRL-3 and MMPs activity.

To dissect the mechanism of MMPs in PRL-3-promoted cell invasion, gelatinolytic activities of MMP2 and MMP9, two key members of MMP family, were examined by a zymographic assay. In brief, concentrated and normalized serum-free medium of LoVo-C and LoVo-P cells, which contained MMPs secreted by cells, were subjected to electrophoresis in a $10 \%$ gel containing the substrate of gela- tin and carried out enzymatic reaction. Bright bands contrasting to dark background indicated the absence of gelatin, which had been hydrolyzed by MMPs running to the corresponding molecular weight. Figure 6B showed that MMP2 activity was strongly increased in the culture medium of LoVo-P cells compared to that of LoVo-C cells. No activity of MMP9 was detected in these cells. It is known that activity of MMP2 is regulated by a dynamic balance between MMP2 and its endogenous tissue inhibitor TIMP2 post-translationally $[42,43]$. To clarify whether increased MMP2 activity resulted from up-regulation of MMP2 or down-regulation of TIMP2, we examined expression of MMP2 and TIMP2 at both mRNA and protein levels in LoVo-C and LoVo-P cells. MMP2 mRNA was
A

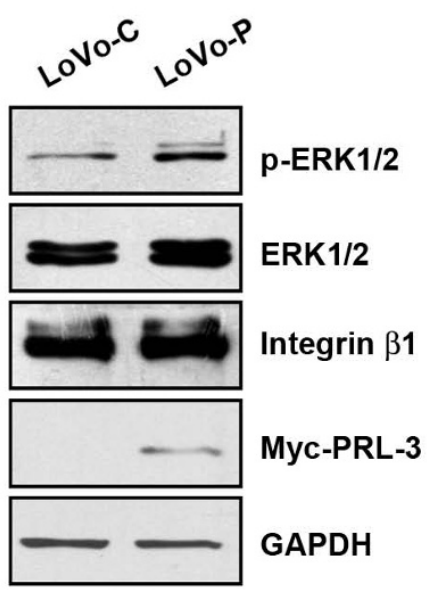

B

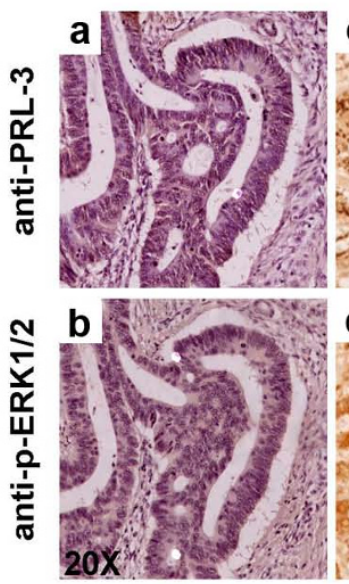

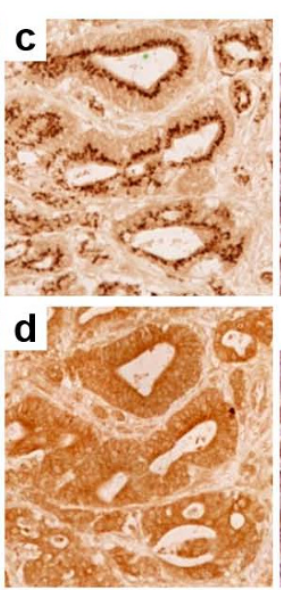

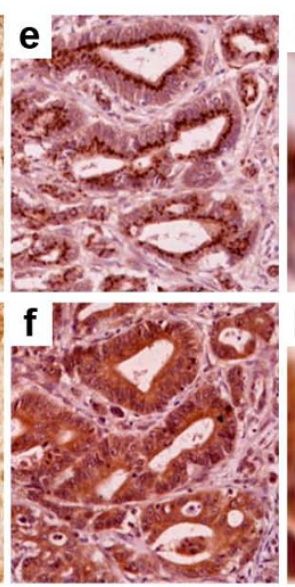

\section{Figure 4}

Correlation between PRL-3 level and ERK phosphorylation. (A) PRL-3 enhanced ERKI/2 phosphorylation in LoVo cells. Equal numbers of LoVo-C and LovO-P cells were cultured for $24 \mathrm{~h}$ with complete medium. Cells were harvested and lyzed. Then cell lysates (50 $\mu \mathrm{g}$ of protein) were subjected to Western blot with antibodies against P-ERK I/2, ERKI/2, Myc-tag (for Myc-PRL-3), integrin $\beta I$, and GAPDH, respectively. (B) Expression of PRL-3 and p-ERKI/2 in primary lesions of human colon cancer tissues was analyzed by an immunohistochemical assay. Two consecutive $4-\mu \mathrm{m}$ paraffin-embedded slices of the same tissue sample were probed with anti-PRL-3 (a, c, e, g) and anti-P-ERKI/2 (b, d, f, h), respectively. The representative negative staining of PRL-3 and P-ERKI/2 in the consecutive slices was shown in a and $b$, and the representative positive staining of PRL-3 and p-ERKI/2 was shown in the c, d, e, f, g, h (c and d, without HE counterstaining; e, f, g, h, with HE counterstaining; $g$ and $h$, enlarged views of $e$ and $f$, respectively). 

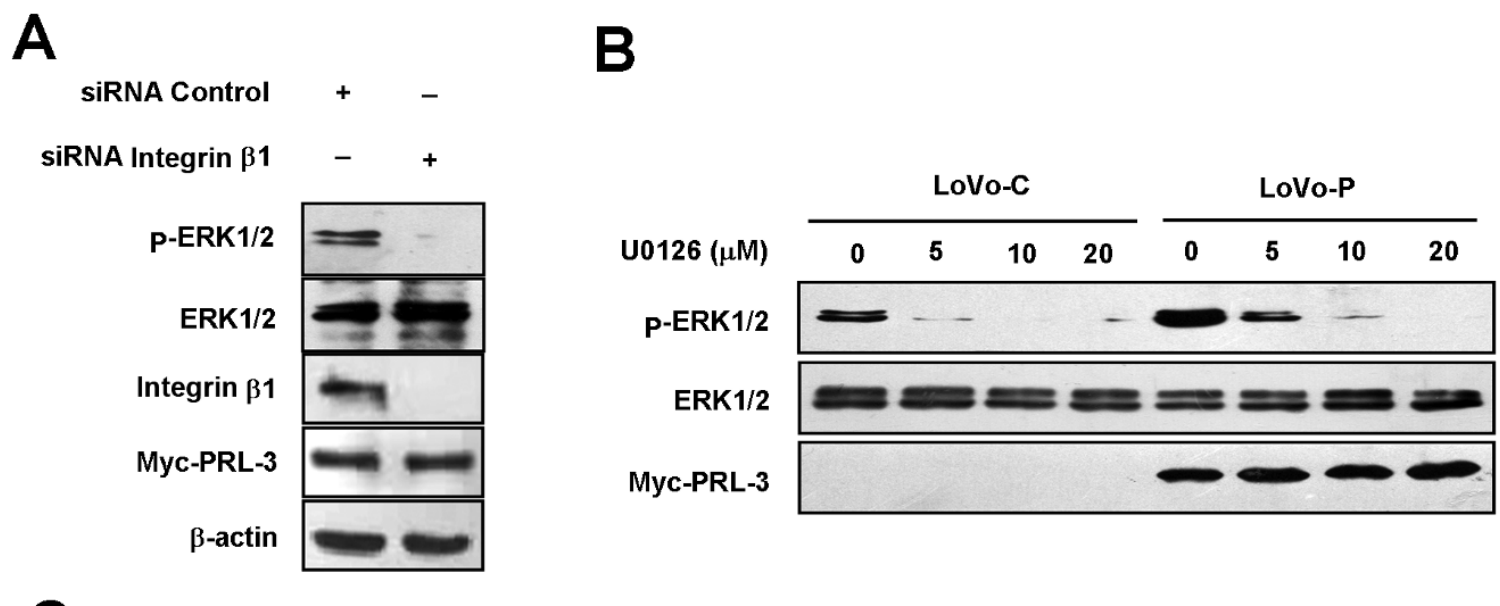

C

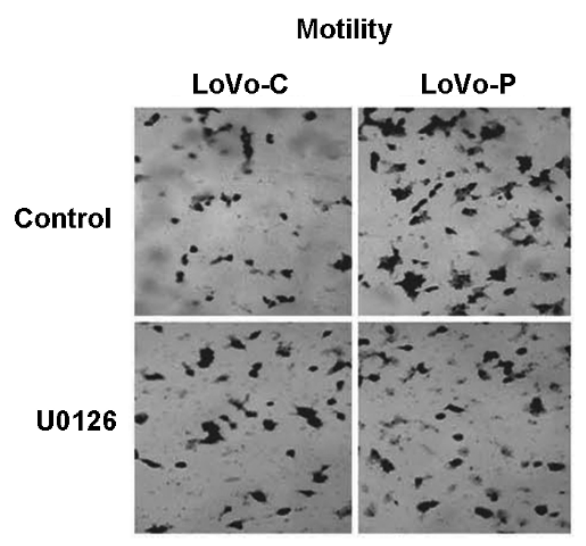

D
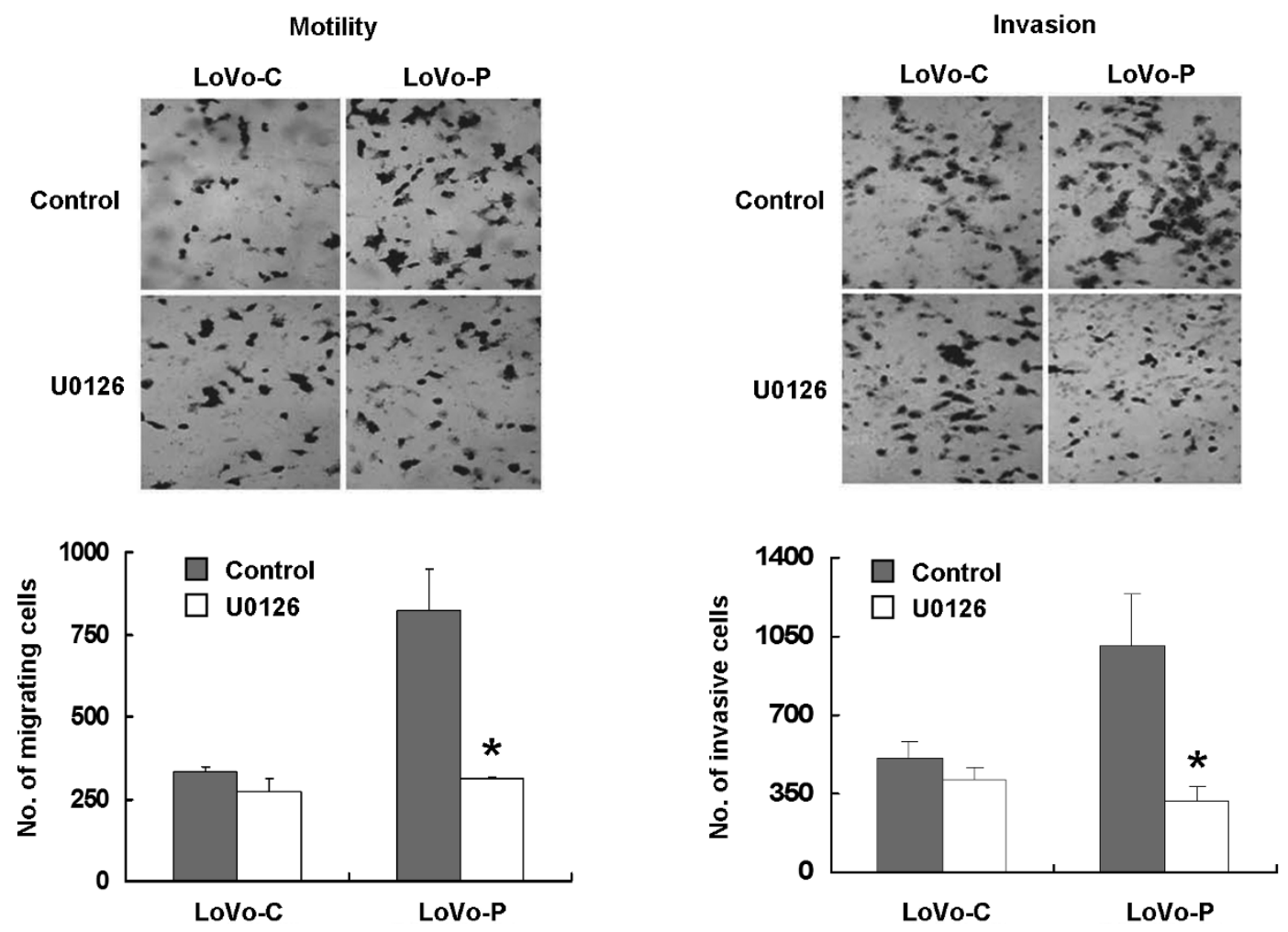

\section{Figure 5}

Integrin $\beta$ I mediates PRL-3-induced ERK I/2 activation. (A) Knockdown of integrin $\beta$ I abolished PRL-3-induced ERKI/ 2 phosporylation. LoVo-P cells were treated with siRNA against integrin $\beta$ I or control for $72 \mathrm{~h}$, and then lysates $(50 \mu \mathrm{g}$ of protein) were subjected to Western blot to analyze the expression of P-ERKI/2, ERKI/2, Myc-tag (for Myc-PRL-3), integrin $\beta I$, and $\beta$-actin (B) UOI26 inhibited PRL-3-induced ERKI/2 phosporylation in a dose-dependent manner. Twenty-four hours after plating, LoVo-C and LoVo-P cells were treated with indicated concentration of U0I26 for I h, and their lysates (50 $\mu \mathrm{g}$ of protein) were analyzed for P-ERKI/2, ERKI/2 and Myc-tag (for Myc-PRL-3) by Western blot. (C) and (D) Inhibition of ERKI/2 activity by $\mathrm{U} 0 \mathrm{I} 26$ abolished PRL-3-induced cell motility and invasion. LoVo-C and LoVo-P cells were treated with $10 \mu \mathrm{M}$ of $\mathrm{U} 0 \mathrm{I} 26$ for I h, and then subjected to motility and invasion assays as described in Figure 2B and 2C, respectively. Values were the total number of stained cells. The experiments were repeated at least three times independently. Error bars represent standard errors of the mean value $(*, P<0.05)$. 
increased in LoVo-P cells, contrary to the decrease of TIMP2 mRNA in LoVo-P cells (Figure 6C, left). At protein level, MMP2 was decreased and TIMP2 were hardly detected in LoVo-P cells (Figure 6C, right). We reasoned that the decrease of MMP2 protein level of LoVo-P cell lysates might result from enhanced secretion of activated MMP2 into the outside of cells or increase of activationinduced MMP2 proteolysis. Therefore, PRL-3 might alter the balance between MMP2 and TIMP2 to facilitate MMP2 activation at multiple levels.

\section{Discussion}

Protein kinases and phosphatases regulate multiple physiological processes $[44,45]$. Phosphatases usually function as tumor suppressors, but some of them have stimulatory effects on cancer-associated processes[46]. PRL-3 is a metastasis-promoting phosphatase $[47,48]$. It has been found to promote metastasis of a variety of cells, including Chinese hamster ovary cell $\mathrm{CHO}$, mouse melanoma cell B16, and gastric cancer cell SGC7901 [18,19,49].

In this study, we examined the roles of integrin $\beta 1$-ERK1/ 2 signaling in PRL-3-facilitating metastasis using human colon cancer cell LoVo, colon cancer tissues from patients, and a metastatic mouse model. We found endogenous integrin $\beta 1$ was associated and colocalized with exogenous PRL-3 in LoVo cells. We tried to explore whether there is a direct interaction between these two molecules by an in vitro binding assay with purified recombinant PRL-3 and cytoplasmic domain of integrin $\beta 1$, however, no interaction was found (data not shown). It's possible that integrin $\alpha 1$ mediated PRL-3-integrin $\beta 1$ interaction, because we previously showed that PRL-3 physically interacted with integrin $\alpha 1$ in HEK293 cells [24]. Unfortunately, integrin $\alpha 1$ protein was not detected in LoVo cells. Whereas in both LoVo-P cells and gastric cancer cells BGC823 stably expressing PRL-3 (BGC823-P), which have detectable integrin $\alpha 1$ on the cell membrane, we observed PRL-3-integrin $\beta 1$ interaction (data not shown), suggesting that such interaction might be indirect and integrin $\alpha 1$-independent, at least for these two cell lines. Besides $\alpha 1$, integrin $\alpha 2-9$ and $\alpha \mathrm{V}$ are also integrin $\beta 1$-binding proteins [33]. Their roles in mediating the PRL-3-integrin $\beta 1$ interaction deserve further exploration.

Here we demonstrated that stable expression of PRL-3 decreased tyrosine phosphorylation of integrin $\beta 1$. Tyrosine phosphorylation of integrin $\beta 1$ has been reported to impair its binding ability with talin [50]. Another study showed that tyrosine dephosphorylation of integrin $\beta 1$ altered its association with actin [51]. Recently, a largescale survey of tyrosine kinase activity in non-small cell lung cancer cell lines identified Y783 of integrin $\beta 1$ as a potential phosphorylation site [52]. However, kinases and phosphatase responsible for tyrosine phoshorylation modification of integrin $\beta 1$ are unknown. Therefore, it remains to be determined whether phosphorylation modification of integrin $\beta 1$ is critical for its signaling transduction and necessary for functions of PRL-3 or whether integrin $\beta 1$ is a substrate of PRL-3.

We also revealed a PRL-3-integrin $\beta 1$-ERK1/2 pathway in controlling motility and invasion of colon cancer cell LoVo. We showed that both activation of ERK $1 / 2$ and the presence of integrin $\beta 1$ were necessary for PRL-3 to promote motility and invasion. Activation of ERK1/2 by PRL3 is dependent on integrin $\beta 1$. Moreover, knockdown of integrin $\beta 1$ efficiently inhibited PRL-3-mediated lung metastasis of LoVo cells in nude mice with a comparable effect to that of silencing of PRL-3. However, the intermediate signaling events between integrin $\beta 1$ and ERK1/2 are still unclear. Activation of ERK is stimulated by both soluble growth factors and integrin-mediated adhesion signals. Integrins intersecting the ERK/MAPK pathway at multiple level, and the crosstalk between growth factors and integrin signaling, give rise to complicated integrin signaling networks and distinctive ERK activation signals [53-55]. To find the intersection point of PRL-3 in the integrin signaling networks would contribute to clarifying the PRL-3 promoted motility, invasion and metastasis. Interestingly, PRL-3 has been reported to activate Src kinase to initiate signaling events, culminating in pathways of ERK1/2, Stat3, and p130cas [21]. Src is one of downstream factors of integrin $\beta 1$ signaling as well as a upstream molecule of ERK activation [56]. Therefore, whether PRL-3 activates ERK1/ 2 through the integrin $\beta 1$ Src pathway or others, such as the integrin $\beta 1$-Grb2 pathway, deserves further exploration. Downstream of the PRL-3-integrin $\beta 1$-ERK1/2 pathway, we found that MMP2 exerted proteolysis function on ECM, a critical event for cancer metastasis. PRL-3 enhanced gelatin hydrolytic activity of MMP2 by increasing MMP2 mRNA and decreasing TIMP2 mRNA and protein. The imbalance of MMP2/TIMP2 expression might account for high MMP2 enzymatic activity imposed by PRL-3 overexpression. In a recent study, PRL-3 expression level was found to be positively correlated with MMP2 activity in high grade of glioma tissues [57], supporting our findings about MMP2 activation in LoVo cells. The precise mechanism of PRL-3 in regulating MMP2 remains to be further clarified.

\section{Conclusion}

Taken together, our results suggest that PRL-3's roles in motility, invasion, and metastasis in colon cancer are critically controlled by the integrin $\beta 1$-ERK1/2-MMP2 signalings. Deeper dissecting the regulation of the PRL-3integrin $\beta 1$-ERK1/2-MMP2 pathway may have a therapeutic implication for prognosis and treatment for colon cancer metastasis. 
A
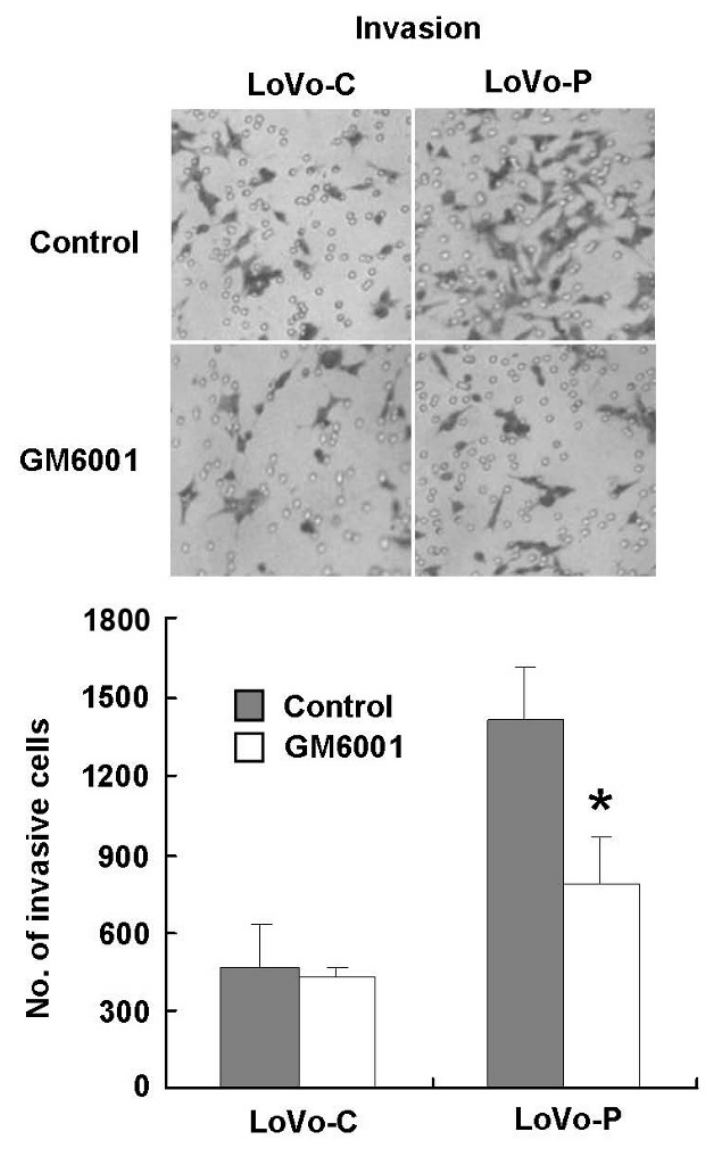
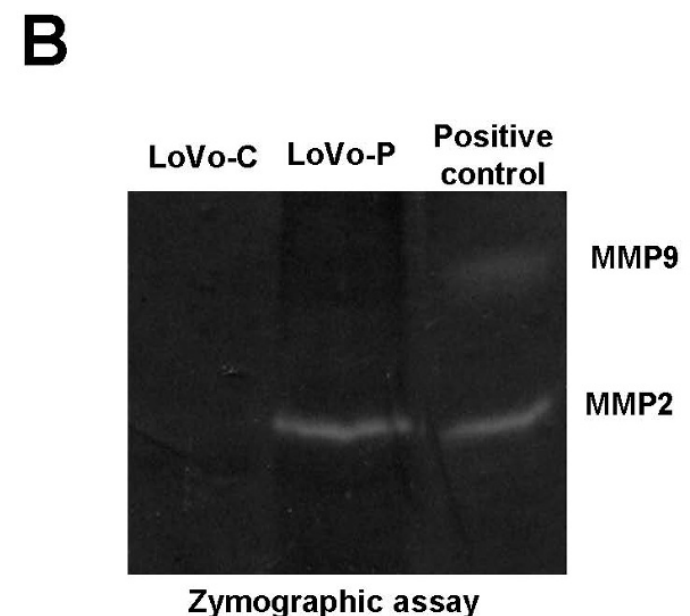

C

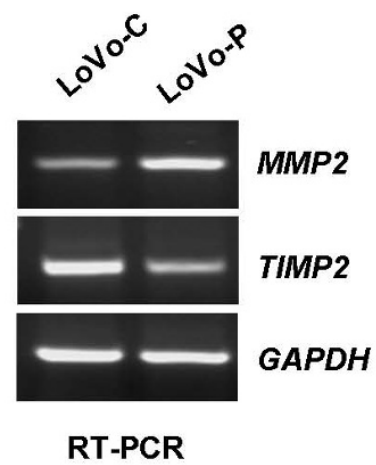

Figure 6

PRL-3 promotes invasion by enhancing MMP2 activity. (A) MMP activity was required for PRL-3-mediated invasion. Cells were treated with $25 \mu \mathrm{M}$ of GM600 I or DMSO (control) for $2 \mathrm{~h}$, and analyzed for their invasion abilities with Matrigelcoated transwell chambers. The invasion assay was performed for three times independently. Top: Representative illustrations of LoVo cells invading to the underside of filters. Bottom: Total number of invasive cells. The experiments were repeated three times independently. Error bars represent standard errors of the mean value $(*, P<0.05)$. (B) PRL-3 increased gelatin hydrolytic activity of MMP2 in LoVo cells. Equal amount of conditioned serum-free media of LoVo-C and LoVo-P cells was subjected to a zymographic assay as described in Experimental Procedures. A small aliquot of calf serum containing MMP9 and MMP2 was included as the positive control. Bright bands contrasting to dark background represented the hydrolysis area of gelatin catalyzed by the MMP at the same molecular weight. (C) PRL-3 affected MMP2 and TIMP2 expression at both mRNA and protein levels. Equal amount of cell lysates ( $50 \mu \mathrm{g}$ of protein) and RNA samples were subjected to Western blot and RT-PCR assays to analyze the expression of MMP2 and TIMP2, respectively.

\section{Abbreviations}

ERK: extracellular signal-regulated kinase; ECM: extracellular matrix; FAK: focal adhesion kinase; GFP: green fluorescent protein; Grb2: Growth factor receptor-bound protein 2; MAPK: mitogen-activated protein kinases; MMP: matrix metalloproteinase; PRL-3: phosphatase of regenerating liver-3; RT-PCR: reverse transcriptionpolymerase chain reaction; shRNA: short hair-pin RNA; siRNA: small interfering RNA; Src kinase: sarcoma kinase.

\section{Competing interests}

The authors declare that they have no competing interests.

\section{Authors' contributions}

LP participated in experimental design, carried out molecular and biochemical analyses, performed in vitro invasion, motility, and animal studies and statistical analysis, interpreted the data and wrote the manuscript. XX participated in molecular and biochemical analyses, performed 
in vitro invasion, motility, wound healing, and immunohistochemical studies and the statistical analysis. WL participated in molecular and biochemical analysis. LQ carried out experimental design and coordination, interpreted the data and wrote the manuscript. LM participated in molecular and biochemical analyses, participated in experimental coordination. SL, BJ and JW participated in molecular and biochemical analyses. CS conceived of the study, carried out experimental design, interpreted the data and wrotet the manuscript. All authors read and approved the final manuscript.

\section{Additional material}

\section{Additional file 1}

Western blot analysis of PRL-3 protein in LoVo cells. LoVo-C and LoVo-P cells were treated with $2 \mathrm{~m}$ Adriamycin or DMSO for $12 \mathrm{~h}$, then cells were harvested and cell lysates (50 g of protein) were subjected to Western blot with antibodies against PRL-3 (Sigma), Myc, p53 (DO-1, Santa Cruz), and GAPDH, respectively. Antibody to PRL-3 recognized exogenous $P R L-3$, but no endogenous $P R L-3$ was detected in both cell lines. LoVo-P cells had more p53 expression, which was consistent with results from Basak et al [Ref [23]].

Click here for file

[http://www.biomedcentral.com/content/supplementary/14764598-8-110-S1.TIFF]

\section{Additional file 2}

Wound healing assay. The effect of PRL-3 on the motilities of LoVo cells analyzed with wound healing assay for $72 \mathrm{~h}$ and the closure of the wound line was recorded every $24 h$.

Click here for file

[http://www.biomedcentral.com/content/supplementary/14764598-8-110-S2.TIFF]

\section{Additional file 3}

Correlation between Expression of PRL-3 and P-ERK1/2 in Human Colon Cancer Tissues. File shows the correlation between expression of PRL-3 and P-ERK1/2 in human colon cancer tissues.

Click here for file

[http://www.biomedcentral.com/content/supplementary/14764598-8-110-S3.DOC]

\section{Acknowledgements}

This study was supported by the National 973 Program (2009CB521805), National Nature Science Foundation of China (30671024 and 30973407) and Natural Science Foundation of Beijing (5072015).

\section{References}

I. Zeng Q, Hong W, Tan YH: Mouse PRL-2 and PRL-3, two potentially prenylated protein tyrosine phosphatases homologous to PRL-I. Biochem Biophys Res Commun 1998, 244:42 I-427.

2. Matter WF, Estridge T, Zhang C, Belagaje R, Stancato L, Dixon J, Johnson B, Bloem L, Pickard T, Donaghue M, et al: Role of PRL-3, a human muscle-specific tyrosine phosphatase, in angiotensinII signaling. Biochem Biophys Res Commun 200I, 283: I06I-I068.

3. Fagerli UM, Holt RU, Holien T, Vaatsveen TK, Zhan F, Egeberg KW, Barlogie B, Waage A, Aarset H, Dai HY, et al.: Overexpression and involvement in migration by the metastasis-associated phos- phatase PRL-3 in human myeloma cells. Blood 2008, I I I:806-8I5.

4. Parker BS, Argani P, Cook BP, Liangfeng H, Chartrand SD, Zhang M, Saha S, Bardelli A, Jiang Y, St Martin TB, et al.: Alterations in vascular gene expression in invasive breast carcinoma. Cancer Res 2004, 64:7857-7866.

5. Rouleau C, Roy A, St Martin T, Dufault MR, Boutin P, Liu D, Zhang M, Puorro-Radzwill K, Rulli L, Reczek D, et al.: Protein tyrosine phosphatase PRL-3 in malignant cells and endothelial cells: expression and function. Mol Cancer Ther 2006, 5:219-229.

6. Saha S, Bardelli A, Buckhaults P, Velculescu VE, Rago C, St Croix B, Romans KE, Choti MA, Lengauer C, Kinzler KW, Vogelstein B: $\mathbf{A}$ phosphatase associated with metastasis of colorectal cancer. Science 200I, 294: 1343-1346.

7. Peng L, Ning J, Meng L, Shou C: The association of the expression level of protein tyrosine phosphatase PRL-3 protein with liver metastasis and prognosis of patients with colorectal cancer. J Cancer Res Clin Oncol 2004, I 30:52 I-526.

8. Wang L, Peng L, Dong B, Kong L, Meng L, Yan L, Xie Y, Shou C: Overexpression of phosphatase of regenerating liver-3 in breast cancer: association with a poor clinical outcome. Ann Oncol 2006, 17:1517-1522.

9. Xing X, Peng L, Qu L, Ren T, Dong B, Su X, Shou C: Prognostic value of PRL-3 overexpression in early stages of colonic cancer. Histopathology 2009, 54:309-3 I8.

10. Ren T, Jiang B, Xing X, Dong B, Peng L, Meng L, Xu H, Shou C: Prognostic Significance of Phosphatase of Regenerating Liver-3 Expression in Ovarian Cancer. Pathol Oncol Res 2009 in press.

II. Radke I, Gotte M, Kersting C, Mattsson B, Kiesel L, Wulfing P: Expression and prognostic impact of the protein tyrosine phosphatases PRL-I, PRL-2, and PRL-3 in breast cancer. $\mathrm{Br}$ J Cancer 2006, 95:347-354

12. Miskad UA, Semba S, Kato H, Yokozaki H: Expression of PRL-3 phosphatase in human gastric carcinomas: close correlation with invasion and metastasis. Pathobiology 2004, 7 I: I76-184.

13. Bardelli A, Saha S, Sager JA, Romans KE, Xin B, Markowitz SD, Lengauer C, Velculescu VE, Kinzler KW, Vogelstein B: PRL-3 expression in metastatic cancers. Clin Cancer Res 2003, 9:5607-5615.

14. Polato F, Codegoni A, Fruscio R, Perego P, Mangioni C, Saha S, Bardelli A, Broggini M: PRL-3 phosphatase is implicated in ovarian cancer growth. Clin Cancer Res 2005, I I:6835-6839.

15. Mollevi D, Aytes A, Berdiel M, Padulles L, Martinez-Iniesta M, Sanjuan $X$, Salazar R, Villanueva A: PRL-3 overexpression in epithelial cells is induced by surrounding stromal fibroblasts. Molecular Cancer 2009, 8:46.

16. Wallin AR, Svanvik J, Adell G, Sun XF: Expression of PRL proteins at invasive margin of rectal cancers in relation to preoperative radiotherapy. Int J Radiat Oncol Biol Phys 2006, 65:452-458.

17. Bessette DC, Qiu D, Pallen CJ: PRL PTPs: mediators and markers of cancer progression. Cancer Metastasis Rev 2008, 27:23I-252.

18. Zeng Q, Dong JM, Guo K, Li J, Tan HX, Koh V, Pallen CJ, Manser E, Hong W: PRL-3 and PRL-I promote cell migration, invasion, and metastasis. Cancer Res 2003, 63:2716-2722.

19. Wu X, Zeng H, Zhang X, Zhao Y, Sha H, Ge X, Zhang M, Gao X, Xu $\mathrm{Q}$ : Phosphatase of regenerating liver-3 promotes motility and metastasis of mouse melanoma cells. Am J Pathol 2004, 164:2039-2054.

20. Fiordalisi JJ, Keller PJ, Cox AD: PRL tyrosine phosphatases regulate rho family GTPases to promote invasion and motility. Cancer Res 2006, 66:3153-3161.

2I. Liang F, Liang J, Wang WQ, Sun JP, Udho E, Zhang ZY: PRL3 promotes cell invasion and proliferation by down-regulation of Csk leading to Src activation. / Biol Chem 2007, 282:54 | 3-54I 9.

22. Wang H, Quah SY, Dong JM, Manser E, Tang JP, Zeng Q: PRL-3 down-regulates PTEN expression and signals through PI3K to promote epithelial-mesenchymal transition. Cancer Res 2007, 67:2922-2926.

23. Basak S, Jacobs SB, Krieg AJ, Pathak N, Zeng Q, Kaldis P, Giaccia AJ, Attardi LD: The metastasis-associated gene Prl-3 is a p53 target involved in cell-cycle regulation. Mol Cell 2008, 30:303-3I4.

24. Peng L, Jin G, Wang L, Guo J, Meng L, Shou C: Identification of integrin alphal as an interacting protein of protein tyrosine phosphatase PRL-3. Biochem Biophys Res Commun 2006, 342:179-183. 
25. Liu S, Thomas SM, Woodside DG, Rose DM, Kiosses WB, Pfaff M, Ginsberg $\mathrm{MH}$ : Binding of paxillin to alpha4 integrins modifies integrin-dependent biological responses. Nature 1999, 402:676-68I.

26. Varner JA, Cheresh DA: Integrins and cancer. Curr Opin Cell Biol 1996, 8:724-730.

27. Burridge K, Chrzanowska-Wodnicka M: Focal adhesions, contractility, and signaling. Annu Rev Cell Dev Biol 1996, I2:463-5 I8.

28. Guo W, Giancotti FG: Integrin signalling during tumour progression. Nat Rev Mol Cell Biol 2004, 5:816-826.

29. Peng L, Li Y, Meng L, Shou C: Preparation and characterization of monoclonal antibody against protein tyrosine phosphatase PRL-3. Hybrid Hybridomics 2004, 23:23-27.

30. Surgucheva IG, Sivak JM, Fini ME, Palazzo RE, Surguchov AP: Effect of gamma-synuclein overexpression on matrix metalloproteinases in retinoblastoma Y79 cells. Arch Biochem Biophys 2003, 410:167-176.

31. Humphries MJ: Integrin structure. Biochem Soc Trans 2000, 28:3II-339.

32. Arao S, Masumoto A, Otsuki M: Beta I integrins play an essential role in adhesion and invasion of pancreatic carcinoma cells. Pancreas 2000, 20:129-I37.

33. Brakebusch C, Hirsch E, Potocnik A, Fassler R: Genetic analysis of beta I integrin function: confirmed, new and revised roles for a crucial family of cell adhesion molecules. J Cell Sci 1997, I I 0(Pt 23):2895-2904.

34. Cheresh DA, Leng J, Klemke RL: Regulation of cell contraction and membrane ruffling by distinct signals in migratory cells. | Cell Biol 1999, |46: I 107-I | I6.

35. Klemke RL, Cai S, Giannini AL, Gallagher PJ, de Lanerolle P, Cheresh DA: Regulation of cell motility by mitogen-activated protein kinase. J Cell Biol 1997, I 37:481-492.

36. Chang C, Werb Z: The many faces of metalloproteases: cell growth, invasion, angiogenesis and metastasis. Trends Cell Biol 200I, I I:S37-43.

37. John A, Tuszynski G: The role of matrix metalloproteinases in tumor angiogenesis and tumor metastasis. Pathol Oncol Res 2001, 7:14-23.

38. Geiger B, Bershadsky A, Pankov R, Yamada KM: Transmembrane crosstalk between the extracellular matrix--cytoskeleton crosstalk. Nat Rev Mol Cell Biol 200I, 2:793-805.

39. Howe A, Aplin AE, Alahari SK, Juliano RL: Integrin signaling and cell growth control. Curr Opin Cell Biol I998, I 0:220-23I.

40. Tan TW, Lai CH, Huang CY, Yang WH, Chen HT, Hsu HC, Fong YC, Tang $\mathrm{CH}$ : CTGF enhances migration and MMP-I 3 up-regulation via alphavbeta3 integrin, FAK, ERK, and NF-kappaBdependent pathway in human chondrosarcoma cells. J Cell Biochem 2009, 107:345-356.

4I. Kuo L, Chang HC, Leu TH, Maa MC, Hung WC: Src oncogene activates MMP-2 expression via the ERK/Sp I pathway. J Cell Physiol 2006, 207:729-734.

42. Yoshizaki T, Sato H, Furukawa M: Recent advances in the regulation of matrix metalloproteinase 2 activation: from basic research to clinical implication (Review). Oncol Rep 2002, 9:607-6II

43. Bode W, Fernandez-Catalan C, Grams F, Gomis-Ruth FX, Nagase H, Tschesche $\mathrm{H}$, Maskos $\mathrm{K}$ : Insights into MMP-TIMP interactions. Ann N Y Acad Sci 1999, 878:73-91.

44. Hunter T: Signaling--2000 and beyond. Cell 2000, 100:113-127.

45. Neel BG, Tonks NK: Protein tyrosine phosphatases in signal transduction. Curr Opin Cell Biol 1997, 9:193-204.

46. Ostman A, Hellberg C, Bohmer FD: Protein-tyrosine phosphatases and cancer. Nat Rev Cancer 2006, 6:307-320.

47. Peng LR, Shou CC: [Phosphatase of regenerating liver-3 (PRL3) and tumor metastasis]. Zhonghua Zhong Liu Za Zhi 2007, 29: 1 -3.

48. Bessette DC, Wong PC, Pallen CJ: PRL-3: a metastasis-associated phosphatase in search of a function. Cells Tissues Organs 2007, I 85:232-236.

49. Li Z, Zhan W, Wang Z, Zhu B, He Y, Peng J, Cai S, Ma J: Inhibition of PRL-3 gene expression in gastric cancer cell line SGC790 I via microRNA suppressed reduces peritoneal metastasis. Biochem Biophys Res Commun 2006, 348:229-237.

50. Tapley P, Horwitz A, Buck C, Duggan K, Rohrschneider L: Integrins isolated from Rous sarcoma virus-transformed chicken embryo fibroblasts. Oncogene 1989, 4:325-333.
5I. Takahashi K: The linkage between betal integrin and the actin cytoskeleton is differentially regulated by tyrosine and serine/threonine phosphorylation of betal integrin in normal and cancerous human breast cells. BMC Cell Biol 200I, 2:23.

52. Rikova K, Guo A, Zeng Q, Possemato A, Yu J, Haack H, Nardone J, Lee K, Reeves C, Li Y, et al:: Global survey of phosphotyrosine signaling identifies oncogenic kinases in lung cancer. Cell 2007, I31:1190-1203.

53. Schwartz MA, Assoian RK: Integrins and cell proliferation: regulation of cyclin-dependent kinases via cytoplasmic signaling pathways. J Cell Sci 200I, I I 4:2553-2560.

54. Schwartz MA, Ginsberg $M H$ : Networks and crosstalk: integrin signalling spreads. Nat Cell Biol 2002, 4:E65-E68.

55. Yee KL, Weaver VM, Hammer DA: Integrin-mediated signalling through the MAP-kinase pathway. IET Systems Biology 2008, 2:8-15.

56. Bouchard V, Harnois C, Demers MJ, Thibodeau S, Laquerre V, Gauthier R, Vezina A, Noel D, Fujita N, Tsuruo T, et al.: B I integrin/Fak/ Src signaling in intestinal epithelial crypt cell survival: integration of complex regulatory mechanisms. Apoptosis 2008 , I3:531-542.

57. Kong L, Li Q, Wang L, Liu Z, Sun T: The value and correlation between PRL-3 expression and matrix metalloproteinase activity and expression in human gliomas. Neuropathology 2007, 27:516-52I.

Publish with Bio Med Central and every scientist can read your work free of charge

"BioMed Central will be the most significant development for disseminating the results of biomedical research in our lifetime. "

Sir Paul Nurse, Cancer Research UK

Your research papers will be:

- available free of charge to the entire biomedical community

- peer reviewed and published immediately upon acceptance

- cited in PubMed and archived on PubMed Central

- yours - you keep the copyright 